\title{
O COMBATE À DESIGUALDADE LINGUÍSTICA NO CURSO DE LE- TRAS - INGLÊS: UM RELATO DA EXTENSÃO UNIVERSITÁRIA
}

COMBATING LINGUISTIC INEQUALITY IN ENGLISH LANGUAGE DEGREE: AN EXPERIENCE REPORT IN UNIVERSITY EXTENSION

\begin{abstract}
Autores
Arthur Bruno Rodrigues Pedrosa. Graduando em Letras - Inglês/Literaturas. Instituto de Letras - Universidade do Estado do Rio de Janeiro (UERJ). Bolsista de extensão - Projeto CEALD (Colaborações, Estratégias de Aprendizado e Letramento digital). E-mail: arthur_pedrosa@hotmail.com
\end{abstract}

Recebido em: 24/01/2019 Aprovado em: 02/02/2019

DOl: $10.12957 /$ interag.2018.39664

\section{Relato}

Este relato de experiência tem o intuito de apresentar a extensão universitária como umas das portas para se combater a desigualdade linguística no curso de Letras - Inglês/Literaturas. O estudo traça um breve panorama da língua inglesa no Brasil e as desigualdades de oportunidade que podem levar a problemas na graduação. $O$ relato justifica-se pela percepção de que muitos alunos não têm o conhecimento linguístico necessário para se manterem de forma satisfatória na universidade, levando a muitas reprovações e à evasão. $O$ projeto base deste relato é o CEALD - Colaborações, Estratégias de Aprendizagem e Letramento Digital: o desafio da equidade na formação de professores de línguas. Seus colaboradores buscam estratégias como cursos, monitoria, etc. com a intenção de ajudar os alunos com dificuldades em língua inglesa e ainda mantê-los interessados na graduação escolhida por eles. O objetivo do relato é o de mostrar como ações de natureza extensionista podem contribuir para sanar ou diminuir essa

\begin{abstract}
This experience report intends to present the university extension as one of the doors to combat linguistic inequality in the course of English / English Literature. The study outlines a brief overview of the English language in Brazil and the inequalities of opportunity that may lead to problems in graduation. The basic project of this report is CEALD - Collaborations, Learning Strategies and Digital Literacy: the challenge of equity in language teacher training. Its collaborators look for strategies such as courses, monitoring, etc. with the intention of helping students with difficulties in the English language and still keep them interested in the graduation chosen by them. The objective of the report is to show how actions of university extension may contribute to solve or reduce this problem, aiming equity in the course. The results show that these students' experiences in the actions are positive. Hence, their view of English language and the course itself may lead them to finish their graduation.
\end{abstract}


problemática, visando equidade dentro do curso. Os resultados obtidos mostram que as experiências desses alunos nessas ações são positivas. Assim, a visão deles em relação à língua inglesa e do curso em si pode levá-los à conclusão da graduação.

Palavras- chave: Direitos Humanos; Extensão; Ensino; Língua inglesa.

Área Temática: Educação

Linha Temática: Formação de professores
Keywords: Human rights; Extension; Teaching; English language.

\section{Introdução}

A extensão universitária possibilita aos seus participantes um contato ainda maior com a realidade da universidade, vez que possibilita buscar, junto à academia, formas do conhecimento produzido por ela de forma significativa à sociedade através de ações que facilitem reduzir ou superar as desigualdades sociais existentes. Sabendo que poucos têm acesso aos conhecimentos gerados na universidade pública, a extensão se torna, então, o caminho para uma maior democratização desse acesso.

Com uma sociedade cheia de desigualdades sociais, é por meio de projetos de extensão, que articulam a pesquisa e o ensino, que se pode alcançar formas de uma busca por um curso com mais equidade. Conforme Cardoso", equidade "não é simplesmente o ato de tratar todos de forma igual, mas fazer com que os não privilegiados tenham as mesmas oportunidades de crescimento que o resto da sociedade em que vivem." Pensando no ambiente acadêmico, é inegável os inúmeros benefícios que a educação de nível superior traz, porém, não adianta apenas garantir que o aluno tenha acesso à universidade, como também é importante que este mesmo aluno consiga superar as dificuldades impostas pelas realidades deste novo ambiente. Muitas vezes as cotas podem ajudar o aluno a ter aprovação no vestibular; no entanto, este mesmo aluno pode se deparar com uma universidade impondo outras barreiras socioculturais. Com a Universidade do Estado do Rio de Janeiro sendo pioneira no sistema de cotas, ou seja, recebendo muitos alunos que tiveram oportunidade de iniciar uma graduação através desse sistema, muitos, infelizmente, chegam à Universidade, mais especificadamente, ao curso de Letras - Inglês/Literaturas com pouco conhecimento da língua inglesa.

\section{O inglês na sociedade e no curso de letras}

Sabe-se que o inglês é a língua que se tornou uma qualificação de muita importância no mundo e cada vez mais pessoas têm buscado estudá-la. No Brasil, ela já é a língua estrangeira mais estudada e, conforme apontado por Leffa ${ }^{2}$ "é falada por mais de um bilhão e meio de pessoas; o inglês é a língua usada em mais de $70 \%$ das publicações cientificas e a língua das organizações internacionais". Além de dominar as produções científicas do mundo, ela ainda é a primeira na internet, mídias sociais, propagandas, etc. Tornou-se, além disso, a língua usada para comunicação entre pessoas de nacionalidades e línguas 
distintas, podendo-se afirmar, conforme Leffa², que "o inglês não tem fronteiras geográficas". Nas palavras de Paiva ${ }^{3}$, tornou a aprendizagem de uma língua estrangeira tarefa "necessária como instrumento de compreensão do mundo, de inclusão social e de valorização pessoal." Desta forma, é importante que o aluno que entra na graduação em língua inglesa, através de uma maior compreensão da língua, sinta-se também incluído no contexto da universidade, levando-o a sua valorização pessoal.

O que influencia de forma negativa na formação deste professor de língua estrangeira, no entanto, é esse aluno chegar ao curso de Letras sem o domínio necessário do inglês para "sobreviver" à graduação. Isso leva muitos estudantes a desistirem/trocarem de curso, ou até mesmo levarem o curso adiante, mas com a frustração de não o acompanhar de forma satisfatória. Esse é o caso do curso de Letras - Inglês/Literaturas da UERJ, visto que muitos dos alunos ingressantes aparentam não terem tido a oportunidade de frequentar cursos de línguas antes da universidade, muitas vezes gerando um número elevado de repetência e até mesmo desistência logo nos primeiros semestres da graduação.

\section{Projeto ceald (colaboracões, estratégias de aprendizagem e letramento digital: o desafio da equidade na formação de professores de línguas}

O professor de língua, porém, como afirma Celani ${ }^{4}$ deveria ser:

um graduado com habilidades para manusear o conhecimento de maneiras definidas, através de uma prática reflexiva, construída ao longo de um processo, com base em uma visão sócio-interacional crítica da linguagem e da aprendizagem; um profissional envolvido em um processo aberto de desenvolvimento contínuo inserido na prática, e não derivado de um método ou de um modelo teórico.

Para formar um profissional de letras, mesmo que apresente dificuldade com a língua inglesa durante o processo de graduação, é necessário então inserí-lo na prática e no aperfeiçoamento tanto de seus conhecimentos linguísticos quanto pedagógicos e foi com esse intuito principal que o projeto surgiu.

Já em 2014 o projeto tem seu início, mas como o de pesquisa "Estratégias de Aprendizagem e Tecnologias de Informação e Comunicação" que depois vira o grupo "EAL - Ensino e Aprendizagem de Línguas: Abordagens, Metodologias e Tecnologias". Ainda como projeto de pesquisa, foi observado, através da realização de entrevistas informais e de avaliação socioeconômica, que o número elevado de reprovação e evasão, ainda nos primeiros períodos do curso de Letras - Inglês estava relacionado ao poder socioeconômico baixo, sendo que muitos dos alunos desistentes não haviam frequentado cursos de idiomas ou tido aulas de inglês regular na escola. Diante dessa constatação, percebeu-se que toda essa recepção popular da Universidade de nada valeria, em vista de uma "seleção natural", na qual os fracos no conhecimento da língua seriam sempre os primeiros a deixar o ambiente acadêmico. Com base nas médias dos alunos e através da realização de testes de nivelamento, buscaram-se, então, estratégias para que esse número de repetentes e desistentes pudesse ser reduzido. Pedido de bolsas para os cursos do Licom (Projeto de extensão intitulado Línguas para a comunidade e que oferece cursos de inglês e outras línguas para a comunidade externa) e a disponibilização da monitoria de Língua Inglesa, que oferece um atendimento personalizado aos alunos, foram as primeiras medidas adotadas. 
Um espaço online (página da monitoria de língua inglesa no Facebook) também foi disponibilizado com links para atividades de desenvolvimento linguístico.

O projeto cresce e, em 2018, surge então o CEALD, de cunho extensionista. O projeto entende a formação do professor como um processo contínuo, que não termina com a graduação. Assim também, por meio de ações extensionistas, com a realização de cursos de curta duração, eventos, oficinas e rodas de leituras, o projeto visa o desenvolvimento linguístico e busca a permanência desses alunos, visto que não é importante apenas garantir o acesso desses alunos à Universidade. Com o desenvolvimento dessas medidas, o propósito principal é o de fornecer maneiras de sanar, ou ao menos reduzir, essas desigualdades dentro do curso. Além de ajudar esses alunos, a intenção também é a de ajudar na atualização de professores - sejam eles da rede pública ou privada - no uso da língua inglesa, visto que muitos também tiveram deficiências nas suas formações, assim como também muitas vezes não podem hoje arcar com cursos de atualização. Desta forma, as ações passam a ser voltadas tanto para os que estão dentro da Universidade quanto para os que já passaram por ela.

A minha experiência dentro do projeto começou efetivamente em março de 2018, com a minha entrada como bolsista de extensão. Dentro do projeto participei das reuniões voltadas a debater as ações a serem implementadas. Eu tinha também como função apoiar nas organizações das oficinas de desenvolvimento de estratégias de aprendizagem; cursos; rodas de leitura; aulões, ajudando na divulgação e no controle das inscrições. Foi uma experiência que contou com a colaboração de participantes do projeto (coordenadora, bolsistas, professores) em que foi colocada em prática a proposta principal do projeto. Em relação a eventos, apresentei o projeto no I SELEIA - Seminário de Ensino de Línguas Estrangeiras na Infância e Adolescência, na IV Jornada de Estudos da Linguagem e na 28음 UERJ SEM MUROS - neste evento recebi também menção honrosa no IX PRÊMIO DE EXTENSÃO PROFESSORA MARIA THERESINHA DO PRADO VALLADARES.

No último trimestre do ano de 2018, eu e os participantes do projeto CEALD desenvolvemos a mais recente ação. Foram oferecidos dois cursos de conversação (um para alunos de nível pré-intermediário e outro intermediário), visando principalmente os alunos iniciantes (primeiro e segundo semestres) e que estavam com suas notas baixas na disciplina de língua inglesa. Apesar de ser de caráter optativo, já que o reconhecimento da necessidade ou não de fazer o curso, além de ser no horário fora do regular dos alunos, dependia de cada pessoa. O curso teve um total de 15 inscrições. Após o encerramento das inscrições, foram feitos nivelamentos para saber os alunos que se encontravam no nível esperado do curso. Com carga horária total de 30h, o curso se tornou uma forma de fazer os estudantes com dificuldade na expressão oral, praticarem sobre temas diversos, escolhidos por eles mesmos. Por não estarem em um ambiente onde estivessem sendo avaliados, sentiram-se mais seguros para se expressarem oralmente.

\section{Considerações finais}

Através de ações extensionistas, também é possível contribuir para sanar ou ao menos atenuar essa problemática de desigualdade linguística. Buscar garantir projetos que ajudem esses alunos, por meio de experiências com a monitoria, de realização de cursos, aulas extras, cursos de línguas livres, entre outras estratégias, o projeto de extensão serve como uma mola para que todos tenham oportunidade alavancar-se e diminuir a desigualdade. Fazendo esse papel, a universidade se demonstra realmente pública, visto que ela 
recebe seus alunos, e também propõe estratégias para mantê-los caminhando em igualdade dentro dela. O papel da extensão vai além ao propor que seus bolsistas pensem em estratégias para os cidadãos do Rio de Janeiro. A universidade pública existe para o povo e para a sociedade em suas várias esferas. $O$ acesso a ela deve ser destinado a todos, reduzindo as muitas desigualdades que existem no país.

\section{Referências}

1. CARDOSO, J. S.The challenge of foresting equity in a TESOL graduate course: $\mathbf{A}$ participatory action research project. In: CARMO, M. Education and new developments 2018. Lisboa, Portugal, 2018. (317-321).

2. $L E F F A, V$. J. Aspectos políticos da formação do professor de línguas estrangeiras. In LEFFA, V. J. (Org.). O Professor de línguas estrangeiras: construindo a profissão. Pelotas: EDUCAT, 2001. p. 10

3. PAIVA, V.L.M.O. A LDB e a legislação vigente sobre o ensino e a formação de professor de língua inglesa.In: STEVENS, C.M.T e CUNHA, M.J. Caminhos e Colheitas: ensino e pesquisa na área de inglês no Brasil. Brasília: UnB, 2003. p.53- 84.

4. CELANI, M. A. A.. Ensino de Língua Estrangeiras: ocupação ou profissão?. In: LEFFA, V. (Org.). O Professor de línguas estrangeiras: construindo a profissão. Pelotas, 2001. V.1 p. 21. 